\section{Low dose intradetrusor injections of onabotulinumtoxin $A$ in women with overactive bladder symptoms or the painful bladder syndrome: unfavorable balance between clinical efficacy and the need for catheterization}

\author{
Jan Groen, ${ }^{1}$ Wouter J.C. Marchand, ${ }^{2}$ \\ Bertil F.M. Blok, ${ }^{1}$ Gert R. Dohle ${ }^{1}$ \\ 'Department of Urology, Erasmus MC, \\ Rotterdam, The Netherlands; \\ 2Department of Urology, Heilig Hart \\ Ziekenhuis, Roeselare, Belgium
}

\section{Abstract}

We evaluated our results with low dose intradetrusor injections of onabotulinumtoxinA in women with overactive bladder symptoms and the painful bladder syndrome in terms of clinically successful outcomes and the need for clean intermittent self-catheterization (CISC) and in relation to urodynamic aspects. The files of patients treated with 100 $\mathrm{U}$ of onabotulinumtoxinA injected at 20 sites with sparing of the trigone were retrospectively analyzed. Nearly all patients completed voiding-incontinence diaries and the King's Health Questionnaire (KHQ) pre- and post-operatively. Cystometric and pressure-flow studies were done in the majority of patients. Success was defined as the patient's and clinician's joint choice for re-treatment with the same dose of onabotulinumtoxinA after a period of at least six months of clinical satisfaction. Twenty-six women were treated. On average, the improvement in most voiding diary parameters and in most KHQ categories lasted less than six and three months, respectively. Eight patients (31\%) were scheduled for re-treatment with $100 \mathrm{U}$ again after at least six months. No prognostic cystometric parameters were found. Six patients (23\%) needed CISC. None of the bladder contraction strength parameters derived from the pressure-flow studies appeared predictive of the need of CISC. We obtained a success rate of $31 \%$ after six months with $100 \mathrm{U}$ of onabotulinumtoxinA, while $23 \%$ of the patients applied CISC. We consider this success rate low and find the balance between the success rate and the rate of patients needing CISC inadequate.

\section{Introduction}

The efficacy of intradetrusor injections of botulinum toxin type A (BTX-A) as a treatment for idiopathic and neurogenic detrusor overactivity (D0) as well as overactive bladder (OAB) symptoms without urodynamically demonstrated DO and the painful bladder syndrome/interstitial cystitis has been demonstrated in randomized clinical trials and (or) case series. ${ }^{1-5}$ The effect of BTX-A on detrusor overactivity is caused by the inhibition of acetylcholine release from presynaptic efferent nerve endings, while its sensory effects are believed to be based on inhibitory effects on the release of several neuropeptides and neurotransmitters from afferent nerves and on the reduction of the levels of nerve growth factor in the urothelium. ${ }^{5,6}$ The most occurring side effect of BTXA treatment is difficulty in voiding, leading to post-void residuals or even urinary retention.,7 The reported rates of patients needing clean intermittent self-catheterization (CISC) vary widely and are approximately $5-45 \% 0^{5,8}$ From a recent dose ranging trial, Dmochowski et al. concluded that $100 \mathrm{U}$ of Botox ${ }^{\circledR}$ (Allergan, Irvine, CA, USA) or onabotulinumtoxinA, a specific formulation of BTX-A, might best balance the symptom benefits with the post-void residual urine volumes. At this dose, 6 (11\%) of the 55 patients needed catheterization. ${ }^{2}$

Intradetrusor injections of onabotulinumtoxinA are applied at our institution since 2004. Indications include OAB symptoms with or without DO (either idiopathic or neurogenic) and symptoms predominated by bladder filling related pain that are refractory to conservative therapy and the inability of patients to tolerate such therapy. The local research ethics committee approved the use of onabotulinumtoxinA for these off-label indications. Initially, the relatively low dose of $100 \mathrm{U}$ was chosen in patients whose voiding was independent of catheterization in order to preserve their voiding function. In the current article, we report on our results with this dose in a first cohort of female patients. Voiding diary results, quality of life effects and urodynamic aspects are considered.

\section{Materials and Methods}

\section{Inclusion of patients}

The files of women treated with $100 \mathrm{U}$ of onabotulinumtoxinA whose voiding was independent of catheterization pre-operatively were reviewed. The onabotulinumtoxinA, diluted in $10 \mathrm{~mL} 0.9 \%$ normal saline to 10 $\mathrm{U} / \mathrm{mL}$, was injected into the detrusor muscle at 20 sites using a $6 \mathrm{~F}$ flexible needle and sparing
Correspondence: Jan Groen, Erasmus MC, Department of Urology, Room EE 1630, P.0. Box 2040, 3000 CA Rotterdam, The Netherlands. Tel: +31.107043377 - Fax: +31.107044726 . E-mail address: j.groen.1@erasmusmc.nl

Key words: bladder, botulinum toxin type A, detrusor overactivity, onabotulinumtoxinA, overactive bladder, painful bladder syndrome, urinary incontinence.

Contributions: JG, data analysis and interpretation, manuscript drafting and final approval; WJCM, study conception and design, data acquisition, manuscript intellectual content and final approval; BFMB, GRD, data acquisition, manuscript intellectual content and final approval.

Conflict of interests: the authors declare no potential conflict of interests.

Received for publication: 31 August 2011.

Revision received: 2 May 2012.

Accepted for publication: 4 October 2012.

This work is licensed under a Creative Commons Attribution NonCommercial 3.0 License (CC BYNC 3.0).

(C)Copyright J. Groen et al., 2012

Licensee PAGEPress, Italy

Urogynaecologia 2012; 26:e10

doi:10.4081/uij.2012.e10

the trigone. The procedure took place under flexible cystoscopic control with the bladder filled to $200 \mathrm{~mL}$ and on an in-patient basis. Patients were under general or spinal anesthesia. This conservative approach was chosen as the described patients were among the first ones treated by us. Patients qualified for treatment if their symptoms of urgency or bladder filling related pain were resistant to conservative therapy or if such therapy could not be tolerated. No specific criteria with respect to voiding diary or urodynamic parameters were required. In particular, the presence of D0 was not a prerequisite for inclusion. The patient's willingness to apply CISC post-operatively if necessary was however a condition for treatment and the technique was instructed preoperatively.

\section{Primary outcome parameters}

Patients were followed-up until the treatment effect had subsided and a decision upon re-treatment had been made. In the current study, clinical success was defined as the patient's and clinician's joint choice for retreatment with the same dose $(100 \mathrm{U})$ of onabotulinumtoxinA. From the clinician's perspective, inherent to this choice was that the patient's satisfaction had lasted for at least 6 months. In agreement with department guide- 
lines, CISC was proposed to the patient during follow-up in case of persistent symptoms in conjunction with post-void residuals above 100 $\mathrm{mL}$. Residuals up to $100 \mathrm{~mL}$ were accepted. CISC was considered needed in this study if it was applied at least once per day during any period of time after hospital discharge.

\section{Additional evaluation tools}

Normally, patients kept 3-day voiding-incontinence diaries and completed the King's Health Questionnaire (KHQ) at baseline and after 1, 3 and 6 months. They also underwent a multi-channel urodynamic examination at baseline, consisting of a cystometric study (filling rate $50 \mathrm{~mL} / \mathrm{min}$, sitting or standing position) and a pressure-flow study. Derived from the cystometric studies were the maximum cystometric capacity and, in case of D0, the maximum detrusor pressure and the threshold volume (the bladder volume at the first involuntary detrusor contraction). Compliance was not considered as there were no subjects with a low compliance bladder. As for the pressure-flow studies, bladder contraction strength and urethral resistance were analyzed in addition to the maximum flow rate $Q_{\max }$, the associated detrusor pressure $\mathrm{p}_{\text {det.Qmax }}$ and the bladder voiding efficiency. ${ }^{9}$ The bladder contraction strength parameters used were: the Watt's factor w (both its maximum value $\mathrm{w}_{\max }$ and its value $\mathrm{w}_{0 \max }$ at maximum flow rate), the bladder contractility index and the projected isovolumetric pressure PIP1.9-11 Urethral resistance was characterized by the average pressure $\mathrm{p}_{\text {lowave }}$ of the low pressure side of the pressure-flow plot, the bladder outlet obstruction index and the urethral resistance factor. ${ }^{9,12}$

\section{Statistics}

Non-parametric tests were used for statistical analysis as no assumptions about the parameter distribution of the population were made. A $\mathrm{P}<0.05$ was considered to represent a statistically significant result. Median values and interquartile ranges are given.

\section{Results}

From April 2004 to December 2006, onabotulinumtoxinA $100 \mathrm{U}$ was injected in 26 women whose voiding was catheterizationindependent. Fourteen patients were under treatment for idiopathic D0, four for neurogenic DO (occult spina bifida, multiple sclerosis, cerebrovascular accident, Parkinson's disease) and three for $\mathrm{OAB}$ symptoms without urodynamically demonstrated D0, while pain was the predominant factor in five patients. Median age in the total group was 58 (45-64) years. The ages in the D0 group (18 patients) were not significantly different from those in the non-D0 group (8 patients). Failed therapies in the 26 patients included: anticholinergics (all patients, mostly because of a lack of effect, occasionally because of side effects), pelvic floor physiotherapy (10 patients), noninvasive types of neuromodulation (5 patients) and invasive types of neuromodulation (10 patients). Additional therapies, mainly bladder dilatations and bladder instillations, had been tried in six of the eight patients of the non-D0 group.

A pre-operative urodynamic examination was done in 23 patients. Tables 1 and 2 (second column) show the results. Two women did not undergo such an examination pre-operatively as they had a prolonged history at our department. They were initially diagnosed with idiopathic DO and the painful bladder syndrome/interstitial cystitis, respectively. A

Table 1. Results of the pre-operative cystometric studies in 23 women treated with onabotulinumtoxinA $100 \mathrm{U}$.

\begin{tabular}{lccc} 
& All patients (23) & DO group (17) & Non-DO group (6) \\
Maximum cystometric capacity $(\mathrm{mL})$ & $260(170-480)$ & $230(130-460)$ & $306(250-481)$ \\
Maximum detrusor pressure $\left(\mathrm{cm} \mathrm{H}_{2} \mathrm{O}\right)$ & $24(8-32)$ & $27(22-37)$ & $6(4-7)$ \\
\hline Threshold volume $(\mathrm{mL})$ & Undefined & $130(87-357)$ & Undefined \\
\hline
\end{tabular}

Median values and interquartile ranges are given. The bladder compliance was normal in all patients. DO, detrusor overactivity.

Table 2. Results of the pre-operative pressure-flow studies and the residue after free uroflowmetry in 23 women treated with onabotulinumtoxinA 100 U. Five women temporarily applied clean intermittent self-catheterization post-operatively.

\begin{tabular}{|c|c|c|c|c|}
\hline - & All (23) & On CISC (5) & Not on CISC (18) & $\mathbf{P}$ \\
\hline End fill volume (mL) & $262(170-430)$ & $270(256-380)$ & $243(130-455)$ & 0.628 \\
\hline Voided volume (mL) & $250(130-360)$ & $262(185-315)$ & $243(130-385)$ & 0.970 \\
\hline Residue (mL) & $0(0-30)$ & $0(0-140)$ & $0(0-33)$ & 0.647 \\
\hline Bladder voiding efficiency (\%) & $100(89-100)$ & $100(62-100)$ & $100(89-100)$ & 0.615 \\
\hline Qmax (mL/s) & $15.5(9.8-20.4)$ & $9.8(7.4-17.3)$ & $16.3(10.9-20.6)$ & 0.192 \\
\hline $\mathrm{P}_{\text {det.Qmax }}\left(\mathrm{cm} \mathrm{H}_{2} \mathrm{O}\right)$ & $25.6(17.9-42.5)$ & $28.9(17.1-54.0)$ & $25.1(17.9-29.9)$ & 0.371 \\
\hline \multicolumn{5}{|c|}{ Bladder contraction strength parameters } \\
\hline $\begin{array}{l}\mathrm{W}_{\max }\left(\mathrm{W} / \mathrm{m}^{2}\right) \\
\mathrm{w}_{\text {Qmax }}\left(\mathrm{W} / \mathrm{m}^{2}\right) \\
\text { BCI } \\
\text { PIP1 }\left(\mathrm{cm} \mathrm{H}_{2} \mathrm{O}\right)\end{array}$ & $\begin{array}{l}7.3(5.6-10.0) \\
6.7(5.3-8.5) \\
98(76-128) \\
42(34-49)\end{array}$ & $\begin{array}{l}7.2(4.8-12.2) \\
6.1(4.7-8.7) \\
91(75-113) \\
38(34-62)\end{array}$ & $\begin{array}{c}7.9(5.7-12.2) \\
6.9(5.3-8.6) \\
110(76-131) \\
43(31-46)\end{array}$ & $\begin{array}{l}0.478 \\
0.737 \\
0.479 \\
0.602\end{array}$ \\
\hline \multicolumn{5}{|l|}{ Urethral resistance parameters } \\
\hline $\mathrm{p}_{\text {low.ave }}\left(\mathrm{cm} \mathrm{H}_{2} \mathrm{O}\right)$ & $19.6(13.9-31.5)$ & $20.2(10.9-43.7)$ & $19.4(13.8-29.6)$ & 0.682 \\
\hline BOOI & $-3.7[(-14.4)-9.9]$ & $9.9[(-16.2)-37.7]$ & $-5.4[(-14.7)-(-0.5)]$ & 0.118 \\
\hline $\mathrm{URA}\left(\mathrm{cm} \mathrm{H}_{2} \mathrm{O}\right)$ & $12.0(8.9-17.9)$ & $17.9(10.2-32.8)$ & $11.7(8.9-13.7)$ & 0.117 \\
\hline Residue after free uroflowmetry (mL) & $0(0-50)$ & $0(0-30)$ & $0(0-50)$ & 0.792 \\
\hline
\end{tabular}

CISC, clean intermittent self-catheterization; BCI, bladder contractility index; BOOI, bladder outlet obstruction index; URA, urethral resistance factor. Median values and interquartile ranges are given. The P values resulted from the Mann-Whitney U test comparing the patients who temporarily applied CISC with those who did not. 
third patient, complaining of urge urinary incontinence after a cerebrovascular accident, did undergo a urodynamic examination at intake. No D0 was diagnosed. She underwent a tension free vaginal tape procedure because of the observed stress urinary incontinence. Next, she was treated with onabotulinumtoxinA because of unaltered symptoms without the urodynamic examination being repeated. Tables 3 and 4 summarize the voiding diary and KHQ results. It can be seen that most voiding diary parameters improved for less than 6 months and that the scores on most KHQ categories improved for less than 3 months.

Re-treatment with onabotulinumtoxinA 100 $\mathrm{U}$, defined as success in this study, was scheduled in 8 patients (31\%): 4 (22\%) from the D0 group and 4 (50\%) from the non-D0 group. These rates were not significantly different $\left(\chi^{2}\right.$ test: $\left.\mathrm{P}=0.157\right)$. Maximum cystometric capacity and the maximum detrusor filling pressure could not be identified as factors predictive of success $(\mathrm{P}=0.141$ and 0.061 , respectively). The same was true for the patient's age. The successfully treated patients had a higher baseline 24-h voiding frequency and daytime voiding frequency than the unsuccessfully treated ones (Table 5). No other voiding diary parameters were significantly different between both groups.

Six patients (23\%) applied CISC during follow-up. The minimum duration of CISC was 4 weeks. Neither age nor maximum flow rate, post-void residual or any of the bladder contraction strength and urethral resistance parameters listed in Table 2 proved to be a prognostic factor for the need of CISC. For none of the six patients was this need a reason to refrain from further onabotulinumtoxinA treatments.

\section{Discussion}

In the current study we evaluated our results of intradetrusor injections of $100 \mathrm{U}$ of onabotulinumtoxinA in 26 female patients who were part of the first cohort of patients treated with this modality at our department. The women constituted a heterogeneous group of idiopathic and neurogenic cases suffering from D0, OAB symptoms without DO or the painful bladder syndrome/interstitial cystitis. They had in common that they could void spontaneously, that is, without assistance by catheterization, before treatment. The low dose of $100 \mathrm{U}$ was chosen to preserve voiding function. Success was defined as the choice for re-treatment with the same dose after at least 6 months of clinical satisfaction. This minimum duration was chosen as it is known

Table 3. Voiding diary results in 26 women treated with onabotulinumtoxinA $100 \mathrm{U}$.

\begin{tabular}{|c|c|c|c|c|}
\hline & Baseline & 1 Month & 3 Months & 6 Months \\
\hline No. of voidings per $24 \mathrm{~h}$ & $\begin{array}{l}13.0(9.3-16.4)[25] \\
12.0(8.2-14.0)[18] \\
14.3(13.0-25.0)[7]\end{array}$ & $\begin{array}{r}9.7(8.3-12.0) *[23] \\
9.7(8.0-11.2) *[17] \\
10.8(8.6-13.3)[6]\end{array}$ & $\begin{array}{r}10.0(9.7-13.2) *[16] \\
9.9(9.5-12.1) *[10] \\
10.9(9.5-16.5)[6]\end{array}$ & $\begin{array}{l}12.3(10.5-13.2)[12] \\
12.3(10.1-14.7)[8] \\
12.0(10.5-13.2)[4]\end{array}$ \\
\hline No. of daytime voidings & $\begin{array}{l}10.7(8.0-15.0)[25] \\
10.0(7.8-13.5)[18] \\
12.3(10.0-20.0)[7]\end{array}$ & $\begin{array}{l}8.0(7.3-10.3) *[23] \\
8.0(6.5-9.0)^{*}[17] \\
9.4(7.5-11.7)[6]\end{array}$ & $\begin{array}{l}9.7(7.8-10.5) *[16] \\
9.7(7.3-10.1) *[10] \\
9.9(8.2-14.5)[6]\end{array}$ & $\begin{array}{c}10.2(9.0-11.8)[12] \\
10.2(9.2-11.8)[8] \\
9.7(8.6-11.8)[4]\end{array}$ \\
\hline No. of nighttime voidings & $\begin{array}{l}2.0(1.0-2.9)[25] \\
1.2(0.6-2.7)[18] \\
2.0(2.0-3.0)[7]\end{array}$ & $\begin{array}{l}1.3(0.7-2.3)[23] \\
1.3(0.5-2.5)[17] \\
1.4(0.9-2.2)[6]\end{array}$ & $\begin{array}{l}1.5(0.8-2.2)[16] \\
1.5(0.5-2.6)[10] \\
1.5(0.8-2.3)[6]\end{array}$ & $\begin{array}{l}2.0(1.1-2.7)[12] \\
2.0(1.0-3.2)[8] \\
1.9(1.1-2.7)[4]\end{array}$ \\
\hline Average voided volume (mL) & $\begin{array}{l}110(80-136)[24] \\
100(81-135)[18] \\
121(68-200)[6]\end{array}$ & $\begin{array}{l}153(97-217) *[22] \\
150(96-218) *[17] \\
156(93-240)[5]\end{array}$ & $\begin{array}{l}161(119-224) *[16] \\
161(120-214) *[10] \\
163(103-240)[6]\end{array}$ & $\begin{array}{l}158(114-225)[12] \\
135(103-198) *[8] \\
200(136-239)[4]\end{array}$ \\
\hline No. of incontinence episodes & $\begin{array}{l}4.0(0.5-8.9)[25] \\
5.3(2.5-12.0)[18] \\
0.0(0.0-4.7)[7]\end{array}$ & $\begin{array}{l}0.3(0.0-2.7) *[23] \\
1.3(0.3-2.9) *[17] \\
0.0(0.0-0.0)[6]\end{array}$ & $\begin{array}{l}1.7(0.0-4.0) *[15] \\
2.7(0.9-4.4) *[9] \\
0.0(0.0-1.4)[6]\end{array}$ & $\begin{array}{l}4.9(0.0-8.3)[12] \\
5.7(1.2-9.8)[8] \\
0.0(0.0-3.8)[4]\end{array}$ \\
\hline No. of pads & $\begin{array}{l}3.4(0.4-6.2)[24] \\
4.0(2.4-7.7)[17] \\
0.0(0.0-4.7)[7]\end{array}$ & $\begin{array}{l}1.3(0.3-2.0)^{*}[20] \\
1.7(0.6-2.8) *[14] \\
0.5(0.0-2.0)[6]\end{array}$ & $\begin{array}{l}2.0(0.0-3.0)^{*}[13] \\
2.7(1.7-3.0)[7] \\
0.7(0.0-2.6)[6]\end{array}$ & $\begin{array}{l}4.6(1.5-7.1)[10] \\
5.7(2.7-7.5)[7] \\
0.0(2.0-4.0)[3]\end{array}$ \\
\hline No. of urgency episodes & $\begin{array}{l}8.0(3.0-11.3)[15] \\
8.3(3.0-11.3)[11] \\
6.0(1.4-22.8)[4]\end{array}$ & $\begin{array}{l}5.0(1.4-9.5)[17] \\
7.4(2.7-9.6)[12] \\
4.5(0.0-10.6)[5]\end{array}$ & $\begin{array}{l}6.7(3.0-9.0)^{*}[11] \\
6.4(2.9-8.7) *[6] \\
6.7(1.9-12.4)[5]\end{array}$ & $\begin{array}{l}8.0(3.7-11.4)[9] \\
8.0(3.7-11.4)[5] \\
7.9(1.9-11.8)[4]\end{array}$ \\
\hline
\end{tabular}

Median values and interquartile ranges are given. Every first line refers to all patients, every second and third line to the patients in the detrusor overactivity (DO) group and the non-DO group, respectively. The numbers in brackets indicate the number of patients constituting the data. *statistically significant difference with respect to the values at baseline (Wilcoxon's matched pairs signed ranks test).

Table 4. King's Health Questionnaire results in 26 women treated with onabotulinumtoxinA $100 \mathrm{U}$.

\begin{tabular}{lcccc} 
& Baseline [19] & 1 Month [22] & 3 Months [15] & 6 Months [12] \\
General health perception & $50(25-50)$ & $50(25-50)$ & $50(25-50)$ & $50(25-69)$ \\
Incontinence impact & $100(100-100)$ & $100(33-100)^{*}$ & $67(33-100)^{*}$ & $100(42-100)$ \\
\hline Role limitations & $100(83-100)$ & $75(33-100)^{*}$ & $67(50-100)^{*}$ & $92(33-100)$ \\
Physical limitations & $100(67-100)$ & $92(33-100)^{*}$ & $83(50-100)$ & $100(54-100)$ \\
\hline Social limitations & $67(33-78)$ & $53(16-70)^{*}$ & $67(0-78)$ & $67(19-89)$ \\
Personal relationships** & $50(17-83)$ & $33(8-83)^{*}$ & $33(0-87)$ & $33(9-92)$ \\
\hline Emotions & $67(44-78)$ & $56(19-67)^{*}$ & $56(33-67)$ & $44(3-78)$ \\
Sleep and energy & $83(50-83)$ & $59(33-100)^{*}$ & $50(33-83)$ & $75(67-100)$ \\
\hline Severity measures & $83(75-100)$ & $83(56-100)^{*}$ & $83(75-100)$ & $83(54-92)$ \\
\hline
\end{tabular}

Median values and interquartile ranges are given. The numbers in brackets indicate the number of patients constituting the data. *statistically significant difference with respect to the values at baseline (Wilcoxon's matched pairs signed ranks test); **item only applicable in $15 / 19,16 / 22,10 / 15$ and $9 / 12$ patients at the respective time points. 
Table 5. Voiding diary results at baseline in 8 and 18 women successfully and unsuccessfully treated, respectively, with onabotulinumtoxinA $100 \mathrm{U}$.

\begin{tabular}{lccc} 
& Successful & Unsuccessful & P \\
No. of voidings per $24 \mathrm{~h}$ & $17.7(13.0-19.3)[7]$ & $11.7(8.0-13.9)[18]$ & 0.018 \\
No. of daytime voidings & $15.0(10.7-17.0)[7]$ & $9.7(7.2-12.5)[18]$ & 0.018 \\
\hline No. of nighttime voidings & $2.7(1.3-3.0)[7]$ & $1.2(0.6-2.6)[18]$ & 0.135 \\
Average voided volume $(\mathrm{mL})$ & $77(68-145)[6]$ & $114(84-152)[18]$ & 0.217 \\
\hline No. of incontinence episodes & $4.7(0-10.0)[7]$ & $3.5(0.8-7.2)[18]$ & 1.000 \\
No. of pads & $4.0(0-7.7)[7]$ & $2.7(0.6-6.2)[17]$ & 0.924 \\
\hline No. of urgency episodes & $10.7(3.7-20.2)[5]$ & $7.7(2.5-10.3)[10]$ & 0.327 \\
\hline
\end{tabular}

Median values and interquartile ranges are given. The numbers in brackets indicate the number of patients constituting the data. The P values resulted from the Mann-Whitney $\mathrm{U}$ test.

that such periods of efficacy are achievable in idiopathic as well as neurogenic cases., ${ }^{1,2,13}$ Contenting oneself with a shorter period would therefore lead to an unnecessarily high treatment frequency, with associated costs and load for the department. From a scientific point of view, the used definition is debatable as the choice for re-treatment depends on subjective factors rather than objective criteria as well as on the availability of alternative options. Clinically, however, the definition is relevant as it indicates whether or not the treatment is valuable for a given patient. With the above definition, we observed a success rate of $31 \%$, while reported success rates in the literature are usually in the range $70-90 \%{ }^{7,8}$ The difference can partly be explained by differences in the definition of success, the length of followup and the injected dose. An amount of $100 \mathrm{U}$, as in our study, is lower than what is generally used. ${ }^{4,13}$ The largest study up to now using this dose was done by Schmid et al. ${ }^{1}$ These authors treated 100 idiopathic overactive bladder patients (men and women). Significant improvement in subjective symptoms, quality of life (KHQ) and urodynamic parameters was found in $88 \%$ after 3 months, while $92 \%$ would be willing to undergo a second treatment. Efficacy duration was about $6 \pm 2$ (range 5-9) months. This seems to be longer than in our study, in which most voiding diary parameters and KHQ scores improved for less than 6 and 3 months, respectively. It should be noted that data is missing in a considerable number of patients, especially at the 3- and 6-month follow-up time points, and that the tables therefore probably overestimate the true effect of treatment as the successfully treated patients tended to have a longer follow-up than the unsuccessfully treated ones. We did not observe a statistically significant difference between the success rates of patients with and without D0. Although the numbers of patients in our subgroups are obviously too small to ascribe any relevance to this finding, the result is in line with those of other authors. ${ }^{1,2}$

Inherent to the mechanism of action of onabotulinumtoxinA is the risk of developing residues. Of our patients, $23 \%$ applied CISC post-operatively. For none of the patients this was a reason to abandon re-treatment. This observation is in line with the results of a study by Kessler et al. ${ }^{14}$ In a group of 65 women treated with $200 \mathrm{U}$ of onabotulinumtoxinA for idiopathic D0, no significantly different quality of life scores were found between the 28 (43\%) women who did and those who did not need CISC. It is nevertheless our experience that the potential need for CISC is a reason to refrain from onabotulinumtoxinA treatment for many patients. Identification of factors predicting the need for CISC would therefore be highly desirable. Pre-operative bladder contraction strength might be such a factor. To our knowledge, this was investigated so far in only one study. In a group of 39 women treated with $200 \mathrm{U}$ of onabotulinumtoxinA for idiopathic D0, Sahai et al. found that the parameter PIP1 was significantly lower in those needing CISC. ${ }^{15}$ Other bladder contraction strength parameters were not considered. We considered several such parameters, but could not draw a similar conclusion. This might be related to our small number of patients as well as to the lower dose and the ability of many women to void by abdominal straining. It is anyway evident that a better insight into the relationship between urodynamic characteristics and the need for CISC would benefit patient counseling.

There is a lack of knowledge on the relationship between the duration of efficacy and the injected dose. ${ }^{16}$ While the results of dose-ranging studies in neurogenic patients are still awaited, such a study on idiopathic overactive bladder patients was recently published. ${ }^{2}$ Dmochowski et al. found that a $50 \mathrm{U}$ dose resulted in a consistently lower non-sustained efficacy than doses of $100 \mathrm{U}$ or greater, while doses of 200 and $300 \mathrm{U}$ did not appear to provide additional efficacy as compared to $150 \mathrm{U}$. In contrast, dose dependent increases up to $200 \mathrm{U}$ were seen in post-void residual volume and the use of CISC. Of the 55 patients who received $100 \mathrm{U}, 6$ (11\%) applied CISC or had an indwelling catheter for a certain (unspecified) period of time. Catheterization rates of $20 \%$ and $21 \%$ were found in the $150 \mathrm{U}$ and $200 \mathrm{U}$ groups, respectively. Based on their results, the authors stated that $100 \mathrm{U}$ might be the dose that appropriately balances the symptom benefits with the post-void residual volume related safety profile. In our view, however, a too short duration of efficacy was generally found in our patient group using this dose. We therefore preferably inject 200 U. Sustained results are usually obtained. The catheterization rate was however not monitored.

\section{References}

1. Schmid DM, Sauermann P, Werner M, et al. Experience with 100 cases treated with botulinum-A toxin injections in the detrusor muscle for idiopathic overactive bladder syndrome refractory to anticholinergics. J Urol 2006;176:177-85.

2. Dmochowski R, Chapple C, Nitti VW, et al. Efficacy and safety of onabotulinumtoxinA for idiopathic overactive bladder: a doubleblind, placebo controlled, randomized, dose ranging trial. J Urol 2010;184:241622.

3. Herschorn S, Gajewski J, Ethans K, et al. Efficacy of botulinum toxin A injection for neurogenic detrusor overactivity and urinary incontinence: a randomized doubleblind trial. J Urol 2011;185:2229-35.

4. Mangera A, Andersson K-E, Apostolidis A, et al. Contemporary management of lower urinary tract disease with botulinum toxin A: a systematic review of Botox (OnabotulinumtoxinA) and Dysport (AbobotulinumtoxinA). Eur Urol 2011;60: 7845.

5. Apostolidis A, Dasgupta P, Denys P, et al. Recommendations on the use of botulinum toxin in the treatment of lower urinary tract disorders and pelvic floor dysfunctions: a European consensus report. Eur Urol 2009;55:100-20.

6. Chancellor MB, Fowler CJ, Apostolidis A, et al. Drug insight: biological effects of botulinum toxin A in the lower urinary tract. Nat Clin Pract Urol 2008;5:319-28. 
7. Dmochowski R, Sand PK. Botulinum toxin $A$ in the overactive bladder: current status and future directions. BJU Int 2007;99: 247-62.

8. Schurch B. Botulinum toxin for the management of bladder dysfunction. Drugs 2006;66:1301-18.

9. Abrams P. Bladder outlet obstruction index, bladder contractility index and bladder voiding efficiency: three simple indices to define bladder voiding function. BJU Int 1999;84:14-5.

10. Griffiths DJ, Constantinou CE, van Mastrigt R. Urinary bladder function and its control in healthy females. Am J
Physiol 1986:251:R225-30.

11. Tan TL, Bergmann MA, Griffiths D, Resnick NM. Stop test or pressure-flow study? Measuring detrusor contractility in older females. Neurourol Urodyn 2004;23: 184-9.

12. van Mastrigt R, Kranse M. Computerassisted pressure-flow analysis. Urol Clin North Am 1996;23:393-405.

13. Patel AK, Patterson JM, Chapple CR. Botulinum toxin injections for neurogenic and idiopathic detrusor overactivity: a critical analysis of results. Eur Urol 2006;50: 684-710.

14. Kessler TM, Khan S, Panicker J, et al.
Clean intermittent self-catheterization after botulinum neurotoxin type A injections: short-term effect on quality of life. Obstet Gynecol 2009;113:1046-51.

15. Sahai A, Sangster P, Kalsi V, et al. Assessment of urodynamic and detrusor contractility variables in patients with overactive bladder syndrome treated with botulinum toxin-A: is incomplete bladder emptying predictable? BJU Int 2008;103: 630-4.

16. Apostolidis A. Pharmacotherapy for overactive bladder: minimally invasive treatment - botulinum toxins. Expert Opin Pharmacother 2011;12:1029-39. 